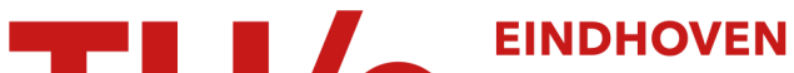 \\ UNIVERSITY OF \\ TECHNOLOGY
}

\section{State-of-charge indication for portable applications}

\section{Citation for published version (APA):}

Pop, V., Bergveld, H. J., Notten, P. H. L., \& Regtien, P. P. L. (2005). State-of-charge indication for portable applications. In Proceedings of the IEEE International Symposium on Industrial Electronics, ISIE 2005, 20-23 June 2005, Dubrovnik, Croatia (pp. 1007-1012). Institute of Electrical and Electronics Engineers. https://doi.org/10.1109/ISIE.2005.1529061

DOI:

10.1109/ISIE.2005.1529061

Document status and date:

Published: 01/01/2005

\section{Document Version:}

Publisher's PDF, also known as Version of Record (includes final page, issue and volume numbers)

\section{Please check the document version of this publication:}

- A submitted manuscript is the version of the article upon submission and before peer-review. There can be important differences between the submitted version and the official published version of record. People interested in the research are advised to contact the author for the final version of the publication, or visit the DOI to the publisher's website.

- The final author version and the galley proof are versions of the publication after peer review.

- The final published version features the final layout of the paper including the volume, issue and page numbers.

Link to publication

\section{General rights}

Copyright and moral rights for the publications made accessible in the public portal are retained by the authors and/or other copyright owners and it is a condition of accessing publications that users recognise and abide by the legal requirements associated with these rights.

- Users may download and print one copy of any publication from the public portal for the purpose of private study or research.

- You may not further distribute the material or use it for any profit-making activity or commercial gain

- You may freely distribute the URL identifying the publication in the public portal.

If the publication is distributed under the terms of Article $25 f a$ of the Dutch Copyright Act, indicated by the "Taverne" license above, please follow below link for the End User Agreement:

www.tue.nl/taverne

Take down policy

If you believe that this document breaches copyright please contact us at:

openaccess@tue.nl

providing details and we will investigate your claim. 


\title{
State-of-Charge Indication in Portable Applications
}

\author{
V. Pop*, H.J. Bergveld**, P.H.L. Notten********, P.P.L. Regtien* \\ ${ }^{*}$ University of Twente/Measurement and Instrumentation, Enschede, the Netherlands \\ ${ }^{* *}$ Philips Research Laboratories/Mixed - Signal Circuits and Systems, Eindhoven, the Netherlands \\ *** Philips Research Laboratories/Integrated Device Technologies, Eindhoven, the Netherlands \\ ${ }^{* * * *}$ Eindhoven University of Technology/Electrochemical Energy Storage, Eindhoven, the Netherlands
}

\begin{abstract}
The known methods of State-of-Charge (SoC) indication in portable applications are not accurate enough under all practical conditions. The method presented in this paper aims at designing and testing an SoC indication system capable of predicting the remaining capacity of the battery and the remaining run-time with an accuracy of 1 minute or better under all realistic user conditions, including a wide variety of load currents and a wide temperature range. The basis of the proposed algorithm is current measurement and integration during charge and discharge state and voltage measurement during equilibrium state. One of the main problems in designing an accurate SoC indication system is aging of the battery. A simple method of adapting the maximum battery capacity used in the system with the aging effects will be presented in this paper. A first set of experimental results shows the effectiveness of our novel approach for improving the accuracy of the SoC indication.
\end{abstract}

Keywords-Li-ion batteries, remaining run-time, portable energy.

\section{INTRODUCTION}

Portable electronic devices have become ubiquitous in modern society. The recent rapid expansion in the use of portable computers, personal data assistants, cellular phones, camcorders and power tools creates a strong demand for fast deployment of battery technologies at an unprecedented rate. The design of such a portable device requires many battery-management features, including charge control, battery-capacity monitoring, remaining run-time information, etc. For offering high precision each part of the system must be near to perfection. In portable applications the request for an accurate and reliable SoC indicator system is clear. This paper deals with this important part of the Battery Management System. As at the moment Li-ion is the most commonly used battery chemistry in the portable applications, we will focus on $\mathrm{SoC}$ indication for $\mathrm{Li}$-ion batteries in this paper.

The SoC is defined as the charge, in [Ah], that is present inside the battery [1]. There are several practical methods available for SoC indication. From these, the direct-measurement and the book-keeping methods [1], [2] are explained in section II of this paper. The main problem in designing an accurate $\mathrm{SoC}$ indication system is the unpredictability of both battery and user behavior. In order to deal with this an adaptive system has to be used, which is based on direct measurement, book-keeping or a combination of the two [1]. An example of an adaptive SoC system will be described in section III.

This paper is organized as follows. Section II describes possible SoC indication methods. The states of our new proposed SoC algorithm are introduced in section III. Implementation aspects of the algorithm are presented in section IV. Section $\mathrm{V}$ focuses on the obtained experimental results. Finally, section VI presents the concluding remarks and future work.

\section{Possible StATE-OF-CHARGE INDICATION METHODS}

The two best known SoC indication methods will be described in this section [1].

The direct-measurement method is based on the measurement of battery variables such as the battery voltage $(V)$, the battery impedance $(Z)$, and the voltage relaxation time $(\tau)$ after application of a current step. The measured battery variable is directly translated into an SoC value using e.g. a look-up table or predetermined function. Most relations between battery variables and the SoC depend on the temperature $(T)$. Therefore, besides the voltage or impedance, the battery temperature should also be measured. The basic principle of an SoC indication system based on direct measurement is shown in Figure 1.

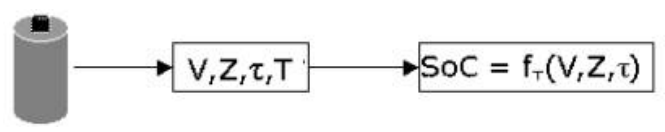

Figure 1. Basic principle of an SoC indication system based on direct measurement [1].

The main advantage of a system based on direct measurement is that it does not have to be continuously connected to the battery. The measurements can be performed as soon as the battery has been connected.

A prime example of a direct-measurement method is voltage measurement. However, although the use of voltage measurement has been a popular method of choice, especially for mobile phone applications, it does not produce the most accurate results available. This method may be less expensive and use less computing power of the processor compared to other methods, but under real-world conditions voltage measurements alone can be very misleading [3]. While it is true that a given cell's voltage level will continually drop during discharge, 
the voltage level's relationship to remaining charge varies greatly over cell temperature and discharge rate. Figure 2 shows a Li-ion's cell voltage curve as a function of SoC in $(\%)$ during discharge at different discharge rates at $25^{\circ} \mathrm{C}$.

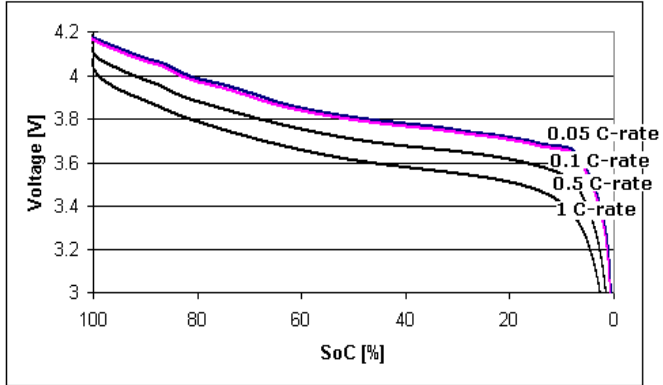

Figure 2. Li-ion cell's voltage curve at different discharge rates at $25^{\circ} \mathrm{C}$.

Figure 2 shows that the voltage discharge curve strongly depends on the discharge rate. The error in SoC estimation based on voltage measurement can be corrected by the system if the cell's temperature and discharge rate are known and all possible curves are stored in the system. However, this will make the process more complicated and expensive than other approaches without providing any significant advantages [4].

A particular method for voltage measurement is represented by the EMF (Electro-Motive Force) method [1]. The EMF is the internal driving force of a battery for providing energy to a load. The battery voltage only equals the EMF when no current flows and the voltage has fully relaxed to its equilibrium value, i.e. the EMF. As soon as we start to (dis)charge, the so-called overpotential (substracts from) adds to the EMF. There are several methods available for the EMF determination, the most practical of which is based on voltage relaxation. The battery voltage will relax to the EMF value after current interruption. This may take a long time especially when the battery is almost empty, at a low temperature and after a previous high discharge current rate [1].

The EMF of a Li-ion battery is observed to be a good measure for a battery's SoC. It has been demonstrated that the relationship between EMF and SoC does not change during cycling of the battery, if SoC is expressed in relative capacity. Temperature dependence of the EMF is small, except when the battery is near to fully discharged or near to fully charged [1].

Book-keeping is a second method for SoC indication that is based on integration of the current flowing into and out of the battery, often referred to as coulomb counting [1], [5]-[8]. However, the battery does not behave like a linear capacitor. This implies that not all charge supplied to the battery can actually be retrieved under all conditions. Therefore, in addition to these coulomb counting data other relevant battery data such as charge/discharge efficiency, self-discharge rate of the battery, temperature, history (i.e. cycle life), etc., will be used as input for the book-keeping system [1]. The basic principle of an SoC indication system based on bookkeeping is shown in Figure 3.

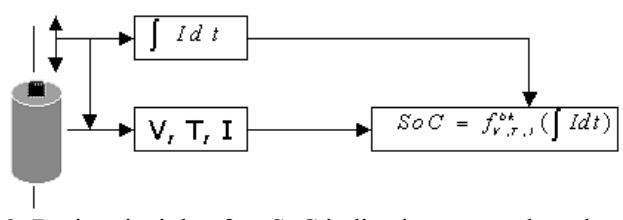

Figure 3. Basic principle of an SoC indication system based on bookkeeping [1].

The overall accuracy of the coulomb counting depends on the accuracy of the current measurement across the full operating range of the battery system, in both the charging and discharging modes. Typically, the current is measured as the voltage across a resistor connected in series with the battery system. The obtained digitised current values are integrated in the SoC system. The larger current levels require substantially lower shunt resistor values and higher power dissipation ratings. The low resistance of such a shunt results in a very small voltage drop across the shunt for lower current levels. Since the function of the battery monitoring system is to provide a time integration of the battery current in order to track the battery's SoC, even small errors in the measurement of the current, e.g. measurement offset, can cause large errors in the SoC measurement to accumulate over time. Therefore, the estimated SoC needs to be calibrated from time to time. This is a disadvantage, since the definition of accurate and useable calibration points is not straightforward.

\section{A NEW SOC INDICATION METHOD}

This paper presents a new method to predict the SoC of a battery that aims at eliminating the main drawbacks and combining the advantages of the methods described in section II. Using this method, the system's estimations are shown to the user in each state in the form of a value of SoC expressed in [\%] and also in the form of a remaining run-time available under the valid discharge conditions. The remaining run-time can be inferred from the remaining capacity in two ways, depending on the type of load [1]: for a current-type load the remaining capacity in [mAh], so expressed as charge, is divided by the drawn current in [mA] and for a power-type load the remaining capacity in [mWh], so expressed as energy, is divided by the drawn power in [mW]. In this paper only current-type loads will be considered for simplicity.

The proposed algorithm operates in five different states [1]: initial state, equilibrium state, transitional state, discharge state and charge state. A description of each state of the algorithm will be given below.

When the battery is first connected to the SoC system, the algorithm starts up in the initial state. In this state the initial SoC is determined based on voltage measurement and the stored SoC-EMF relationship. Dependent on whether the battery is charged, discharged or in equilibrium, the algorithm then shifts to the appropriate state.

In the equilibrium state hardly any current is drawn from the battery. For example, this situation occurs when a mobile phone is in standby mode. The current in this 
case is only a few $\mathrm{mA}$, which is lower than a small current $\mathrm{I}_{\text {lim }}$ defined in the system (e.g. $2 \mathrm{~mA}$ mean in a mobile phone application). For this very low current value, the battery voltage is very close to the EMF value, under the condition that the voltage is stable. Therefore, in order to allow the algorithm to change to this state, the condition of a stable voltage has to be met. In this state the SoC is determined based on voltage measurement and the stored SoC-EMF relationship. Results of our mathematical EMF implementation will be presented in section IV.

The transitional state is used when the algorithm changes from either the charge or the discharge state to the equilibrium state. In this state it is determined whether the battery voltage is stable and the algorithm is allowed to enter into the equilibrium state.

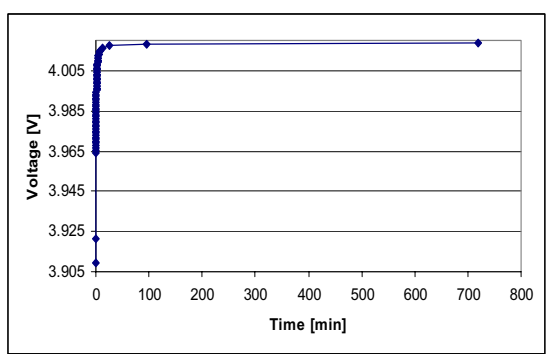

Figure 4. Voltage relaxation after a discharge current step of $0.5 \mathrm{C}$ rate at $82 \%$ SoC and $25^{\circ} \mathrm{C}$.

Figure 4 illustrates what happens to the battery voltage after a discharge step. The value of the OCV (Open Circuit Voltage) changes from about $3.909 \mathrm{~V}$ directly after the current interruption to about $4.019 \mathrm{~V}$ after 720 minutes. It can be observed that the OCV is constant after about 95 minutes. The voltage after 25 minutes differs by approximately $1.6 \mathrm{mV}$ from the voltage after 720 minutes. This means that when we consider for this example that the equilibrium state has been entered after 25 minutes the inaccuracy into the SoC indication will be about $0.17 \%$.

In the discharge state, the battery is discharged and a negative current larger than $\mathrm{I}_{\mathrm{lim}}$ is flowing out of the battery. In addition to simple coulomb counting also the effect of the overpotential is considered. As will be shown in section $\mathrm{V}$ of this paper the prediction of the overpotential yields also a remaining run-time prediction. Due to this overpotential, the battery voltage during the discharge state is lower than the EMF. The value of the overpotential depends on the discharge current, the SoC, age and temperature. Especially for old cells, at low temperatures and at low SoC, due to a high overpotential the remaining charge cannot be withdrawn from the battery, because the battery voltage will drop below the End-of-Discharge voltage defined in the portable device (e.g. $3 \mathrm{~V}$ ). This leads to an apparent capacity loss, which at low temperatures of e.g. $0^{\circ} \mathrm{C}$ amounts up to more than $5 \%$ [1]. Hence, a distinction should be made between available charge in the battery (i.e. SoC) and the charge that can be withdrawn from the battery under certain conditions, expressed in remaining run-time. As overpotentials are temperature-dependent, temperature measurements are also needed in the discharge state.
Results of our mathematical overpotential equation will be presented in section IV.

In the charge state, a charger is connected to the battery and a positive current larger than $\mathrm{I}_{\mathrm{lim}}$ is flowing into the battery. The SoC is determined by coulomb counting. The stable conditions of the charge state will be used in order to adapt our system with the aging effect. One of the main advantages, which is also independent of the type of the used charge method, is that during the charge state the environmental temperature is constant in most practical cases.

It is a fact that in practice any battery will lose capacity during cycling. A simple method for updating the maximum capacity $\mathrm{Q}_{\max }$ to take capacity loss into account will be described below. As shown in Figure 5, for the update mechanism of the maximum capacity, it is necessary for the system to run through a sequence of states: equilibrium state, charge state, transitional state and equilibrium state.

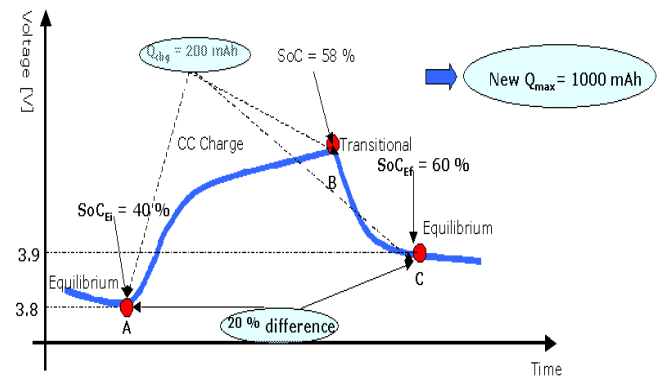

Figure 5. Simple method for updating $\mathrm{Q}_{\max }$ to take capacity loss into account.

As can be seen from the example given in Figure 5 the initial $\mathrm{SoC}_{\mathrm{Ei}}$ before starting charging is $40 \%$. This value is calculated based on the stored SoC-EMF relationship. When a charger is connected to the battery a positive current is flowing into the battery. During charging coulomb counting is applied. At the end of the charge state, based on the coulomb counting, we measured that e.g. $\mathrm{Q}_{\text {chg }}=200 \mathrm{mAh}$ has flown into the battery. At this moment, based on a previous $\mathrm{Q}_{\operatorname{maxp}}$ value (e.g. 1110 $\mathrm{mAh}$ ) and equation (1), we calculate an SoC of $58 \%$.

$$
\operatorname{SoC}[\%]=\operatorname{SoC}_{E_{i}}+\frac{Q_{\text {chg }}}{Q_{\max p}} * 100
$$

After a certain rest period, we enter again into the equilibrium state. Based on the stored SoC-EMF relationship a new $\mathrm{SoC}_{\mathrm{Ef}}=60 \%$ is indicated.

It can be concluded from the previously described situation and equation (2) that a new value for the maximum capacity is $1000 \mathrm{mAh}$.

$$
Q_{\max }[m A h]=\frac{100}{\left(S o C_{E_{f}}-S o C_{E_{i}}\right)} * Q_{c h g}
$$

In summary, in which state the algorithm is operating depends on the value and sign of the current, which is flowing into or out of the battery and whether the battery voltage is stable. The state diagram illustrating the basic structure of the algorithm is shown in Figure 6 [1]. 


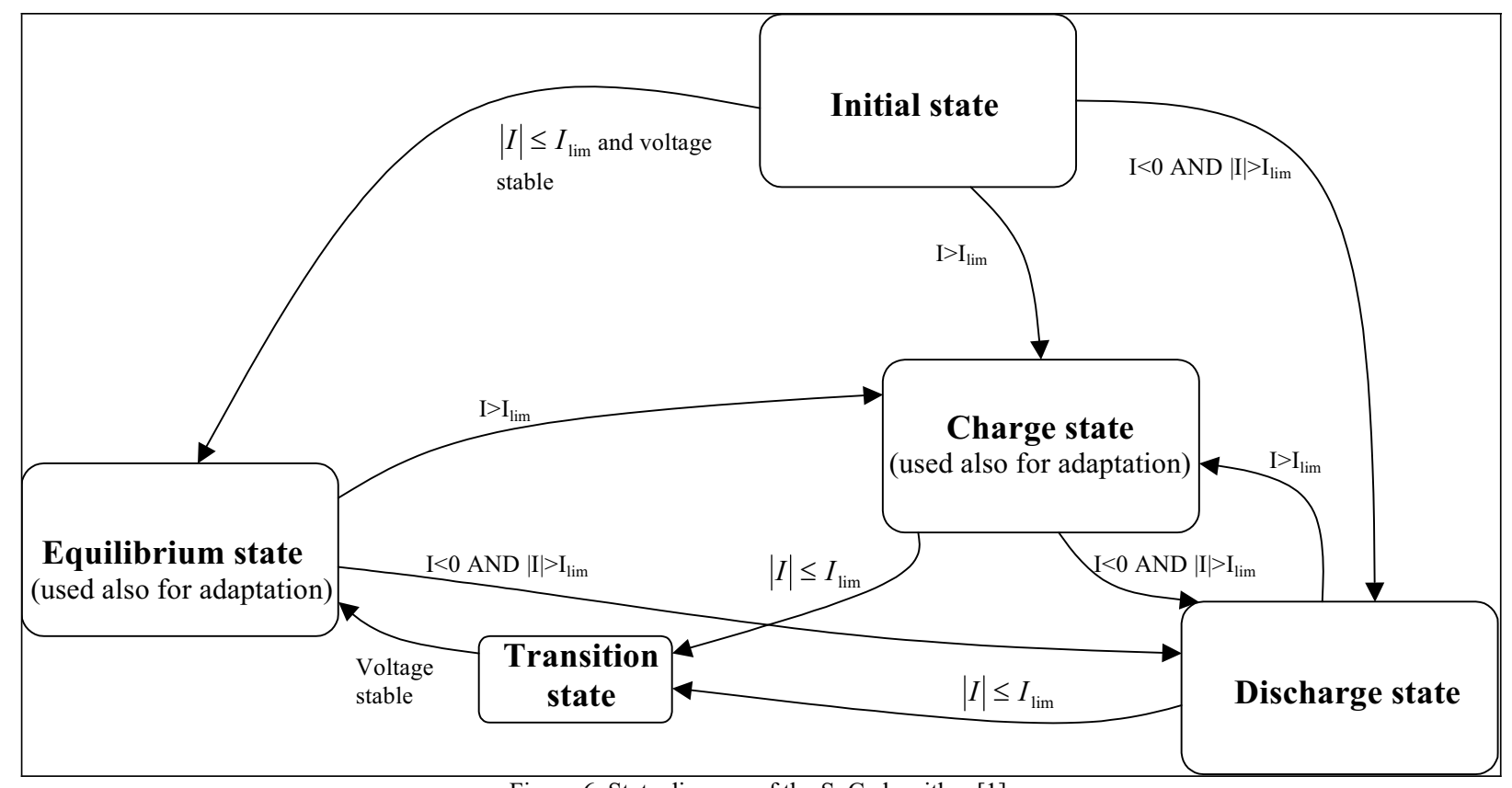

Figure 6. State diagram of the SoC algorithm [1].

\section{IMPLEMENTATION ASPECTS OF THE ALGORITHM}

As previously mentioned, the battery $\mathrm{SoC}$ is determined based on the SoC-EMF relationship during the equilibrium state. The results of our mathematical implementation of the EMF function in the SoC system will first be presented in this section.

The Sony US18500G3 Li-ion battery has been used throughout the experiments. The rated capacity of this battery is $1100 \mathrm{mAh}$. The EMF equations described in [1] as a difference between the equilibrium potentials of the positive and negative electrodes need to be fitted to a measured EMF curve. Figures 7 and 8 show that the fitted EMF curve used in our system fits the measured curve obtained with the Maccor battery tester very well at $25^{\circ} \mathrm{C}$. In all the cases the SoC error is lower than $0.8 \%$ SoC. The SoC error has been obtained as the absolute value of the SoC difference between the fitted value and the true value obtained from the Maccor battery-tester measurements.

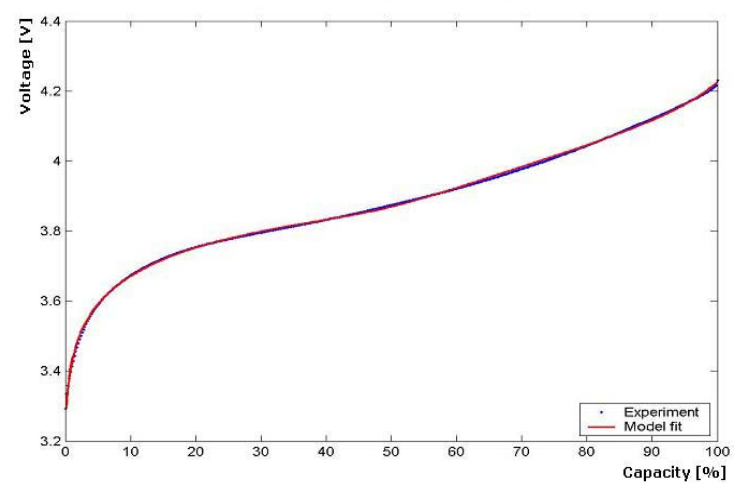

Figure 7. EMF curve measured with Maccor battery tester and fitted EMF curve using our mathematical implementation at $25^{\circ} \mathrm{C}$.

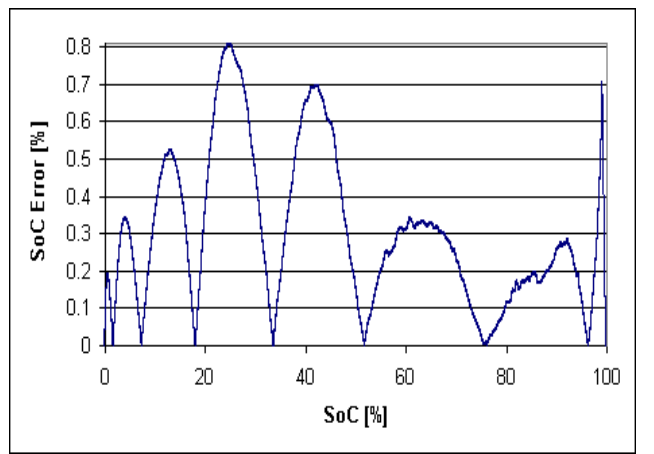

Figure 8. Accuracy of the SoC indication using the measured EMF curve versus the fitted EMF curve (absolute values).

It can be concluded from Figure 8 that the maximum error in SoC is obtained at around $25 \%$ SoC. This low SoC error $(0.8 \%)$ corresponds to a low capacity value, which can still be removed from the battery (around 8.8 $\mathrm{mAh}$ ). As can be calculated from equation (3), even for a fresh cell, at $25^{\circ} \mathrm{C}$ and at a low mean discharge rate $\mathrm{C}_{\mathrm{dschg}}$ (e.g. $0.4 \mathrm{C}$-rate) this implies around 1.2 minutes of remaining run-time $t_{r e m}$.

$$
t_{\text {rem }}[\mathrm{min}]=\frac{S o C[\%]}{100} * \frac{1}{C_{d s c h g}} * 60
$$

Therefore, it can be concluded that the produced error due to the EMF implementation will generally provide us enough accuracy in order to achieve a final accuracy of 1 minute of the remaining run-time indication.

During the discharge state, apart from simple coulomb counting, also the effect of the overpotential is considered. Based on our mathematical implementation of the overpotential [1], in which the ohmic, kinetic, diffusion and increase of the overpotential when the battery becomes empty are considered, and the measured EMF, the measured and fitted overpotential at four different discharge current rates as a function of the relative SoC are illustrated in Figure 9. The measurements have been carried out at $25^{\circ} \mathrm{C}$. 


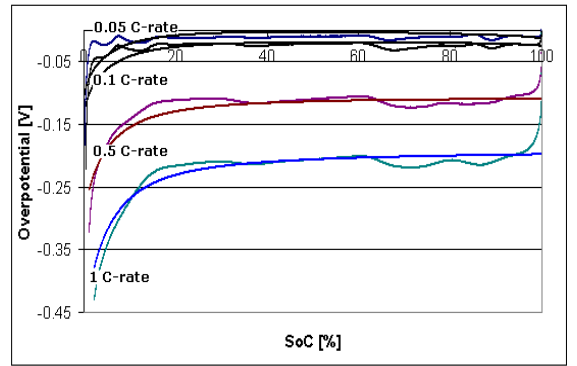

Figure 9. Overpotential curves measured (labelled $m$ ) at $25^{\circ} \mathrm{C}$ at various discharge rates (Maccor battery tester) and corresponding fitted results obtained from our mathematical implementation.

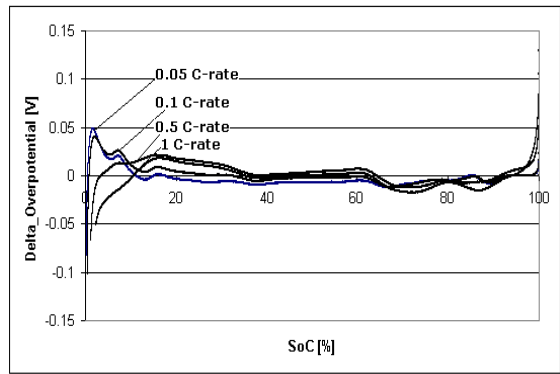

Figure 10. Accuracy of the fitted overpotential curves versus the overpotential curves measured with the Maccor battery tester.

It can be concluded from Figure 10 that the maximum difference between the measured (labelled $m$ ) and the fitted overpotential is obtained for the 0.1 C-rate discharge current at low SoC. In this situation, at $0.56 \%$ SoC the obtained difference has a value of around -100 $\mathrm{mV}$. This voltage error corresponds to a low capacity value $(\mathrm{SoC}=0.25 \%$ or $2.75 \mathrm{mAh}$ ), which still can be removed from the battery. Even for a fresh cell, at $25^{\circ} \mathrm{C}$ and at a low mean discharge rate (e.g. 0.4 C-rate) this means that the SoC system will indicate around 22 seconds more remaining run-time than in the real case (see equation 3 ). In the majority of the cases we obtain a very good fit (under $10 \mathrm{mV}$ difference) between the two curves.

It can be concluded that the produced error by the overpotential implementation will generally provide us enough accuracy in order to achieve a final accuracy of 1 minute of the remaining run-time indication.

\section{EXPERIMENTAL RESULTS}

Even though the EMF and the overpotential functions achieve good accuracy results, a performance analysis of the full SoC algorithm under a real-time laboratory set-up remains necessary in order to check the accuracy of the full algorithm.

The SoC indicator presented in this paper has been tested together with the bq26500 gas gauge IC by Texas Instruments [9] to make a comparison. The bq26500 gas gauge monitor has been chosen, because it is one of the most advanced SoC indicators commercially available. Using the $V, T$ and $I$ measurement inputs the bq 26500 runs a book-keeping algorithm to calculate the SoC. Battery capacity is automatically recalibrated in the course of a discharge cycle from full to empty [9]. The first set of tests has been limited to full charge/discharge cycles at different constant C-rates. The battery has always been fully charged until $4.2 \mathrm{~V}$ with the normal Constant-Current-Constant-Voltage (CCCV) charging method [1] at different C-rates of $0.25,0.5$ and $1 \mathrm{C}$-rate, respectively. In the $\mathrm{CV}$ mode the voltage has been kept constant at $4.2 \mathrm{~V}$ until the current reached a $0.05 \mathrm{C}$-rate value. At the end of the $\mathrm{CV}$ mode we define the $\mathrm{SoC}$ level to be $100 \%$. Each step of charging has been followed by a rest period of about 60 minutes. After this rest period we applied a discharge step until the battery voltage reached $3 \mathrm{~V}$ at different constant C-rates of 0.25 , 0.5 and $1 \mathrm{C}$-rate, respectively.

The Sony US18500G3 Li-ion battery has been used throughout the tests. At the time of testing, the battery was fairly new, with approximately 9 discharge/charge cycles in its history. All the experiments have been carried out with the same battery and at $25^{\circ} \mathrm{C}$.

An important advantage of our indicator is that based on coulomb counting during the charge state and based on coulomb counting and the overpotential function for the discharge state a remaining run-time indication is provided. In Table 1 we have summarised the experimental results. Column one gives the discharge $\mathrm{C}$ rates of the tests. The remaining run-time of our indicator in hours, minutes and seconds predicted at the start $\left(\mathrm{t}_{\mathrm{rems}}\right)$ and indicated at the end $\left(t_{\text {reme }}\right)$ of the tests, is given in columns two and three, respectively. Columns four and five denote the $\mathrm{SoC}$ indications at the end of the experiment of our $\left(\mathrm{SoC}_{\mathrm{P}}\right)$ and of the $\mathrm{TI}$ indicator $\left(\mathrm{SoC}_{\mathrm{TI}}\right)$.

TABLE 1. MEASURED RUN-TIME AND SOC ACCURACY FOR OUR SYSTEM AND THE TI BQ26500.

\begin{tabular}{|c|c|c|c|c|}
\hline C-rate & $\begin{array}{c}\mathrm{t}_{\text {rems }} \\
{[\mathrm{h}: \mathrm{m}: \mathrm{s}]}\end{array}$ & $\begin{array}{c}\mathrm{t}_{\text {reme }} \\
{[\mathrm{h}: \mathrm{m}: \mathrm{s}]}\end{array}$ & $\begin{array}{c}\mathrm{SoC}_{\mathrm{P}} \\
{[\%]}\end{array}$ & $\begin{array}{c}\text { SoC } \\
{[\%]}\end{array}$ \\
\hline 0.25 & $4: 03: 43$ & $0: 01: 28$ & 0.6 & 0 \\
\hline 0.5 & $2: 00: 48$ & $0: 02: 09$ & 1.7 & 0 \\
\hline 1 & $0: 59: 33$ & $0: 01: 47$ & 2.8 & 0 \\
\hline
\end{tabular}

Let us consider for example the $0.25 \mathrm{C}$-rate. At the start of discharge, the system indicated 4 hours 3 minutes and 43 seconds remaining run-time. After 4 hours, 2 minutes and 15 seconds our battery reached the level of 3 $\mathrm{V}$, which means that our inaccuracy is 1 minute and 28 seconds. This value is near to our goal of one-minute accuracy.

It appears from these tests that the TI indicator is more accurate with respect to the SoC indication. The TI system indicates always $0 \%$ SoC at the $3-\mathrm{V}$ battery voltage level. However, as can be seen in Figure 11 some shortcomings have been revealed in the case of the TI indicator.

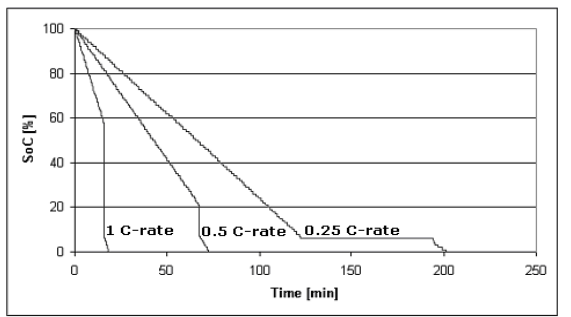

Figure 11. Measured TI SoC indication accuracy. 
In Figure 11 the TI SoC predictions are plotted as a function of time obtained from the experimental tests. First of all, the figure illustrates that the predictions at all discharge rates show a strange "jump" in SoC at a certain SoC level, e.g. from $20 \%$ to $7 \%$ at the 0.5 C-rate. Secondly, long before the end of the experiment, e.g. at 85 minutes for the 0.5 C-rate, where the experiment lasted around two hours, the SoC prediction of the TI gas gauge is already $0 \%$. Our system predicts $\mathrm{SoC}$ values slightly higher than $0 \%$ at $3-\mathrm{V}$ battery voltage for all discharge rates.

It can be concluded from these tests that our indicator performs better for small and high discharge C-rates. However, our indicator makes a slightly optimistic estimation: the user thinks that there is still e.g. 1 minute 28 seconds remaining run-time at a $0.25 \mathrm{C}$-rate, but the battery is suddenly empty. The TI indicator makes a consistently very pessimistic estimation: the user will recharge the battery, while he/she could still use it. Our aim is to predict the remaining run-time exactly or slightly pessimistically, which is an important advantage in comparison with the TI gas gauge.

A second series of tests has been carried out for our indicator to test the maximum capacity adapting mechanism explained in section III. First, an arbitrary maximum capacity of $600 \mathrm{mAh}$ has been programmed into the system. Then, starting from the equilibrium state and a calculated $\mathrm{SoC}_{\mathrm{Ei}}$, we charged our battery with 175.7 $\mathrm{mAh}, 878 \mathrm{mAh}$ and $1109 \mathrm{mAh}$ capacity, respectively. Each charge state was followed by a rest period in which the algorithm was allowed to enter the equilibrium state. In this state an $\mathrm{SoC}_{\mathrm{Ef}}$ value has been calculated. Based on the obtained results and equation (1) we have calculated a new $\mathrm{Q}_{\max }$ value. Table 2 shows the results.

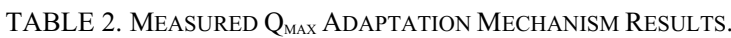

\begin{tabular}{|c|c|c|c|}
\hline $\mathrm{SoC}_{\mathrm{Ei}}[\%]$ & $\mathrm{SoC}_{\mathrm{Ef}}[\%]$ & $\mathrm{Q}_{\mathrm{chg}}[\mathrm{mAh}]$ & $\mathrm{Q}_{\max }[\mathrm{mAh}]$ \\
\hline 0 & 15.78 & 175.7 & 1113 \\
\hline 1.4 & 79.4 & 878 & 1125 \\
\hline 0 & 100 & 1109 & 1109 \\
\hline
\end{tabular}

As can be seen in Table 2, the correct calculated maximum capacity obtained from a full charge has a value of $1109 \mathrm{mAh}$. It can be concluded from these tests that in all of the cases the $\mathrm{Q}_{\max }$ adaptation mechanism will generally provide us with enough accuracy in order to achieve a final accuracy better than $16 \mathrm{mAh}$. Even for a fresh cell, at $25^{\circ} \mathrm{C}$ and at a low mean discharge rate (e.g. $0.4 \mathrm{C}$-rate) this means that we will indicate around 2 minutes more remaining run-time than in the real case. In the near future, we will carry out more improvements in order to achieve better accuracy in all the cases.

\section{CONCLUSIONS}

A new State-of-Charge (SoC) indication algorithm has been presented, which calculates the $\mathrm{SoC}$ in percent, as well as the remaining run-time for a portable application.

A particular method used for the presented SoC indication scheme is the EMF method. The advantage of this method is that the EMF curve does not depend on many parameters. It does not depend on aging and temperature of the battery, so it is a good candidate for the SoC indication. The main drawback of the EMF method is that it does not provide continuous indication of the SoC. Therefore, the proposed SoC system also uses coulomb counting and overpotential prediction.

As has been shown in this paper significant improvement of the fitting results compared to [1] of the EMF and the overpotential functions have been obtained. Using these two functions the prediction of the remaining run-time was generally better than two minutes.

A simple adaptive method for the maximum capacity has been described. The presented adaptive system should improve the system capability of coping with the aging effects [1].

In the near future, we plan to reduce the required rest period for the EMF determination and to predict this value already during the transitional state. Also, more tests at different conditions (e.g. different temperatures, currents and aged batteries) will be carried out in order to improve the accuracy of our novel method of SoC indication.

\section{ACKNOWLEDGMENT}

The authors would like to acknowledge Bert Op het Veld, Dmitry Danilov and Niels Korver for contributing to the measurements and the mathematical modelling.

\section{REFERENCES}

[1] Henk Jan Bergveld, Wanda S. Kruijt, Peter H. L. Notten, "Battery Management Systems, Design by Modelling", Philips Research book series, vol. 1, Kluwer Academic Publishers, Boston, 2002

[2] Bergveld; Hendrik Johannes; Feil; Hans; Van Beek; Johann Reiner Godefridus Cornelis Maria, "Method of predicting the state of charge as well as the use time left of a rechargeable battery", US Patent $6,515,453$, filed November 30, 2000

[3] Dallas Semiconductors, "Lithium-Ion Cell Fuel Gauging with Dallas Semiconductor Devices", App. Note 131, September 2000

[4] Dallas Semiconductors, "Inaccuracies of Estimating Remaining Cell Capacity with Voltage Measurements Alone", App. Note 121, 2000

[5] J.H. Aylor, A. Thieme, B.W. Johnson, "A Battery State-of-Charge Indicator for Electric Wheelchairs", IEEE Trans. on industrial electronics, vol. 39, no. 5, pp.398-409, October 1992

[6] Kikuoka; Takao; Yamamoto; Hiroaki; Sasaki; Noriyoshi; Wakui; Kotaro; Murakami; Keinosuke; Ohnishi; Kazunori; Kawamura; Gou; Noguchi; Hiroshi; Ukigaya; Fumio, "System for measuring state of charge of storage battery", US Patent 4,377,787, filed August 8, 1980

[7] Seyfang; George R., "Battery state of charge indicator", US Patent 4,949,046, filed June 21, 1988

[8] Verbrugge; Mark William; Tate, Jr.; Edward Dean; Sarbacker; Shawn D.; Koch; Brian James, " Quasi-adaptive method for determining a battery's state of charge", US Patent 6,359,419, filed December 27, 2000

[9] Texas Instruments, "Single-Cell Li-ion and Li-Pol Battery Gas Gauge IC For Handheld Applications (bq Junior Family)", Doc. I.D. SLUS567A, October 2003 